scientists, environmental scientists and others to participate in discussions about risk analysis and public policy. Her point that risk assessments involve value judgements beyond the realm of pure science is well taken.

Countering the industry's spin on the benefits of biotech in both developed and developing countries, Caruso focuses on the dark side of genetically modified crops. Her book echoes many of the themes from Deborah Koons Garcia's The Future of Food, a documentary film that attacks all unsustainable and chemically intensive modern agriculture (www.thefutureoffood.com). Unfortunately, Caruso's reliance on websites, unofficial reports and news media for citations means that many of her findings should be checked for accuracy and context. For example, she describes reports that the cultivation of genetically modified crops has already harmed soil organisms, created superweeds, contributed to severe economic hardships, and made people and livestock sick by increasing their exposure to herbicides. Similar criticisms could be made of some non-transgenic crops. Indeed, certain transgenic crops offer greater health benefits than their conventionally produced counterparts. Regarding Terminator technology for producing non-viable seeds, she states that "critics fear that these plants would irreversibly spread their sterility to non-transgenic crops and across species to other plants by contamination". However, these yet-to-be-released crops would not bear viable offspring and so could not spread their genes through reproduction.

Caruso's fears that transgenes could spread willy-nilly to the genomes of unrelated plants and animals - and even to humans - are overly paranoid because distantly related multicellular organisms are not capable of interbreeding. In a flight of hyperbole, she states: "Billions of transgenics have already been released into the marketplace and thus into our food, our water and the air that we breathe, breeding and exchanging their genetic material with each other and with us." But perhaps today's hyperbole could be a prelude to the future, if GMOs are released indiscriminately around the world.

Reading Intervention made me more aware of the value of confronting uncertainty in the complicated process of assessing risks and benefits. This ambitious and engaging book does a good job of defending the layperson's frustrations and concerns about genetically modified organisms.

Allison Snow is in the Department of Evolution, Ecology and Organismal Biology, Ohio State University, Columbus, Ohio 43210, USA.

\section{MORE ON GENETIC ENGINEERING GM Crops: The Impact and the Potential/ Seeds for the Future: The Impact of Genetically Modified Crops on the Environment}

by Jennifer A. Thomson

CSIRO Publishing/University of Cornell Press

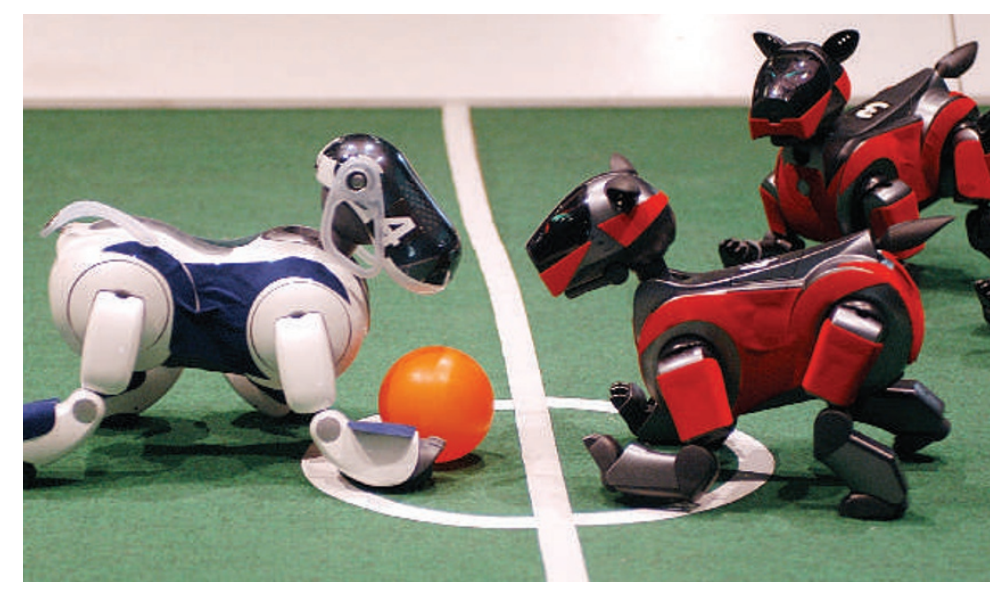

Playing ball: robots must collaborate if they are to succeed at team sports.

\title{
Intelligence in a changing world
}

\section{How the Body Shapes the Way We Think: \\ A New View of Intelligence \\ by Rolf Pfeifer \& Josh Bongard \\ Bradford Books: 2006. 394 pp. \\ $\$ 39.95, £ 25.95$}

\section{Hiroaki Kitano}

The study of intelligence, once dominated by biologists, has for decades been a focus for computer scientists. The question of whether a machine can be intelligent is as old as computers themselves, but was thrust into the spotlight ten years ago when IBM computer Deep Blue beat world champion Garry Kasparov at chess. Whether it really showed intelligence as we know it is still a matter for debate, but researchers have identified that 'intelligence' in the context of chess depends on having a huge database, computing power to search for moves and the ability to learn from past games to obtain a 'goodness score' for each possible move.

However, there are clear differences between the way humans and computers play chess: a chess computer, unlike a human, does not have a body to enable it to interact with its environment, for example. This distinction differentiates two views on intelligence. One view is that intelligence is independent of the body and is unaffected by its existence, shape and function. The other view is that intelligence is contained within a physical body and that the body shapes the mind, an idea often referred to as physical embodiment or the presence of a behaviour-based agent. There is increasing recognition in the artificialintelligence and robotics communities that the nature of the body significantly affects the mind, although it does not totally control it.

How The Body Shapes The Way We Think by Rolf Pfeifer and Josh Bongard provides an excellent perspective on how artificial-intelligence and robotics researchers have been tackling this issue. It is full of examples and thought-provoking discussions so that readers can easily follow some of the central debates on intelligence developed over decades. It also presents a chronological development of the field where appropriate.

The major focus of this book is to discover the design principle of an intelligent agent that has a physical and mobile body, has a high degree of autonomy, interacts with its environment and exhibits a broader range of behaviours than those single-task chess computers. It is not a book about how the body of an existing life form shapes its own mind, so there are only limited references to biology and neuroscience. Nevertheless, there are several parallels between artificial systems and biological systems. In one of the design principles, the authors point out the importance of redundancy, which also applies to biological systems. Some of these commonalities between artificial and biological systems can be seen as system-level principles that seem fundamental to a system's ability to exhibit intelligence, at least to an observer's eye.

One salient difference between the intelligent agents discussed in this book and traditional artificial-intelligence systems, as represented by chess computers, is the contextual thickness of system behaviours. Many of the robotics systems discussed in the book can cope, at least to some extent, with changes in the expected environment, tasks and other assumed conditions, whereas chess computers and other traditional artificial-intelligence systems are usually extremely fragile when faced with even a small change in such conditions. Behaviourbased robots should be able to perform almost flawlessly if the size of road or unevenness of terrain deviates from the initial assumption. However, the results will be catastrophic if a chess computer is given a chess board with nine rows and columns, rather than eight, as they are tuned specifically for the existing rules of chess. Imagine a thought experiment on a chess game between a behaviour-based system and an existing chess computer. The chess computer would be unbeatable with the defined rules, but if the rules were modified the behaviour-based system may do better.

The authors discuss learning, development 
and evolution, an approach inspired by, but not identical to, the biological one. These are methods designed to cope with complex, open and dynamic environments in which predefined rules cannot properly define behaviours because of the overwhelming complexity and difficulty in describing the situation. So artificial agents have to evolve, undergo development and learn how to behave. The authors also discuss the social aspect of multiple agents, or collective intelligence. How do agents with different expertise collaboratively accomplish complex tasks of the sort seen in real society or in sports such as football? These features are considered to be critically important for a multi-agent robotics team to play football in the RoboCup (www.robocup. org). The book beautifully illustrates the development of ideas, why we need these ideas, and what the issues are.

The book focuses on artificial agents, but with a lot of inspiration from nature. This reflects the synthetic approach to understanding: by building intelligent systems we can reach a deeper understanding of intelligence in general. Biologists often criticize such approaches as not being faithful to the biological processes that inspired them. However, researchers in artificial intelligence and robotics are, for example, trying to find out how to design an aircraft inspired by bird flight, instead of replicating a bird itself. It was a huge step in engineering when bird flight was decomposed into thrust and lift, and re-implemented by fixed wings and engines to create modern aircraft. Memory, computing and learning have been similar elements of intelligence in chess machines. The grand question behind this book is the search for such essential ingredients for intelligence in an open, dynamic environment.

Hiroaki Kitano is director of Sony Computer Science Laboratories, 3-14-13 HigashiGotanda, Shinagwa, Tokyo 141-0022, Japan.

\section{Surrealism bites back}

\section{Sink your teeth into Jean Painlevé's nature films at an exhibition in London.}

\begin{abstract}
Martin Kemp
The success of nature documentaries on television rests on their ability to show us the wonders of the natural world. Intimate scenes such as a shimmying sea urchin embedding itself in sand no longer surprise, despite the unfamiliarity of the subject, thanks to the skill of the film-makers.

Rather more surprising is the fact that the first sustained use of film technologies to create moving images of nature's secrets occurred not within the world of professional science, but in the artistic context of surrealism.

The surrealist movement, led by Salvador Dalí, Max Ernst, André Breton and André Masson, regularly exploited biomorphic shapes in strange, dream-like contexts. The organic realm came to be populated by the unfamiliar, the uncanny and the downright sinister.

The development of film techniques resulted in a kind of 'natural surrealism'. The pioneer was Jean Painlevé, who in collaboration with Geneviève Hamon carved out a long career from 1925 to 1975 as the master of the genre. He used it to serve both science and art cinema. Painlevé is now little known, but makes a welcome appearance in the exhibition 'Surreal Things', which can be seen at the Victoria and Albert Museum in London until 22 July.

Painlevé, whose mathematician father twice became prime minister of France, was trained as biologist. He then embarked on a professional career as an actor and became involved in the anarchy of Parisian avantgarde art. His films, all short documentaries, range from soberly descriptive (although always with a strange lyricism) to overtly whimsical and ghoulish. He worked with leading experimental composers to choreograph his work - and used the music of Louis Armstrong and Duke
\end{abstract}

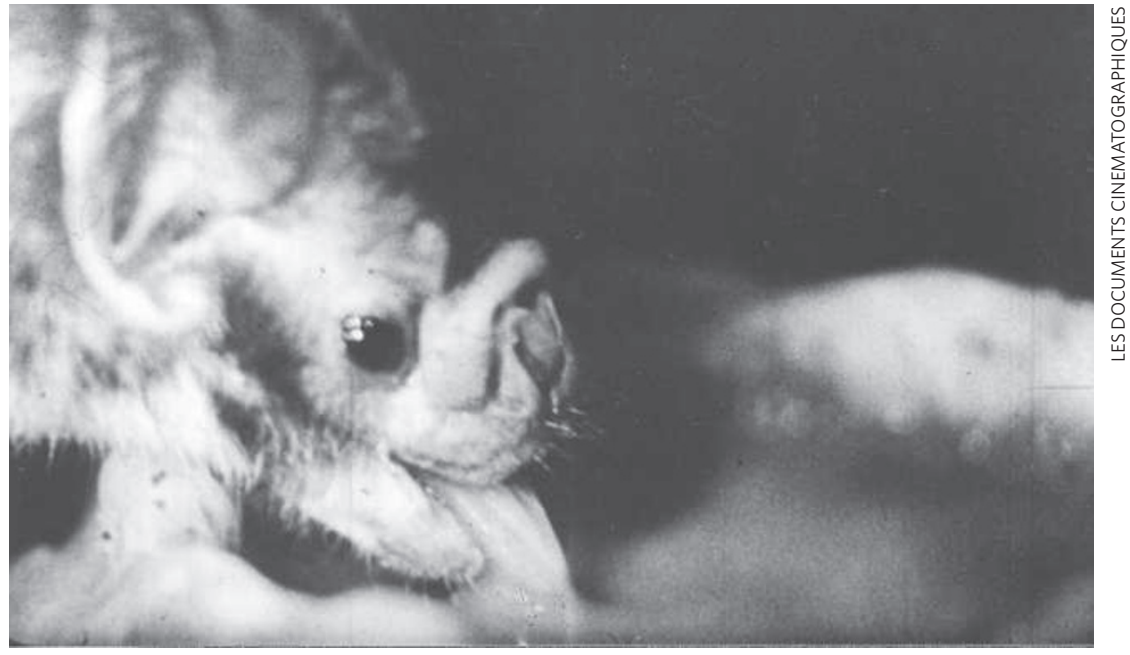

Ellington in his soundtracks.

Some of Painlevé's films, such as Sea Urchins from 1929, rely on descriptive commentaries and direct filming. The drama of these films comes from the camera work, printing and cutting. The beauty of the living and moving sea urchin is seductively captured, although the vivisection of a specimen to show its hugely efficient digestive tract induces a shiver of horror. As Painlevé claimed: "Scientific film requires study and instruction; it is not only a tool, but a grammar and an art."

Other films are self-consciously melodramatic. The Vampire, which is just 9 minutes long, opens with some closeup shots of voracious animals in action, including caterpillars that munch insatiably and blood-sucking leeches. It then stars a vampire bat feasting on the blood of a compliant guinea pig (see picture).

The bat, accompanied by Ellington's jaunty Echoes of the Jungle, unconsciously overacts in a way that would suit the most lurid of horror films - a parallel drawn in Painlevé's film by some short clips from F. W. Murnau's silent film Nosferatu (1922). Murnau's dark masterpiece of expressionist cinema, based on Bram Stoker's Dracula, had precociously used microphotography to portray a 'vampire polyp'.

Composed during the Second World War, The Vampire served as an allegory of Nazism. The implication is that Hitler's fascism infects the mind just as rabies from the blood-sucking bat infects the bodies of its victims.

Nature 'red in tooth and claw' has traditionally provided a source of drama for artists. The nature revealed by film in general - and by the underwater camera, time-lapse and micro-photography in particular - provided the alert surrealists with a disturbing vocabulary of form and motion that was well matched to their purposes.

Martin Kemp is professor of the history of art at the University of Oxford, Oxford OX1 1PT, UK. His latest book, Seen | Unseen, is published by Oxford University Press. 